\title{
A Byzantine Cranium from Jordan: A Case Study in Dental Anthropology
}

\author{
Abdulla Al-Shorman* \\ Department of Anthropology, Yarmouk University, Irbid-Jordan
}

ABSTRACT: This study describes a Byzantine cranium from an archaeological site in Jordan (Khirbit Yajuz). This case study illustrates severity of the multiple dental pathologies encountered and speculates on the cause of death. The 21-yers-old female of this study suffered multiple dental abscesses, where the accumulated pus

The study of the total collection of the human teeth from the archaeological site of Khirbit Yajuz has revealed striking results, notably conspicuous oblique dental wear on the first lower molars, premortem and perimortem tooth loss, dental abscesses in the maxilla, and progressive periodontal disease (AlShorman, 2003). The frequency of dental caries among the recovered skeletons ( $\mathrm{n}=120$ individuals) is $13.3 \%$, which is within the range of the other Byzantine sites in the region (Smith et al., 1992; Williams et al., 2004). These and other archaeological results suggest a population of low social status whose primary occupation was weaving (Al-Shorman and Khalil, 2006). In the upper jaw, most of the sites of tooth decay had developed into dental abscesses. In contrast, the low frequency of caries and the absence of dental abscesses in the lower jaw might have been triggered by the use of teeth as tools (Al-Shorman, 2003) that frequently polished the occlusal tooth surface, thereby removing sticky food particles and reducing depths of the fissures. In other words, the rate of dental wear was high enough to inhibit the development of dental caries on the occlusal surfaces of teeth (Powell, 1985). The frequency of dental abscesses among the Byzantine people of Khirbit Yajuz was extraordinarily high compared to similar sites; most of the investigated carious lesions had periapical abscesses.

A periapical abscess develops when the area surrounding the tip of the root is invaded by bacteria; fluids and dead bacteria accumulate in the periapical region, forming a pocket as part of the phagocytic defense process (Scott and Turner, 1988). Abscesses develop as the fluids break through the alveolar bone. An untreated case may develop a fistula either on the buccal or the lingual side (Alexandersen, 1967). A periapical abscess typically is the result of pulp exposure due to rapid attrition, caries, trauma, or periodontal disease (Hillson, 1996); all of these factors reached the nasal cavity and the maxillary sinuses through a large fistula, probably causing septicemia that may have caused her early death. This case was selected from among similar cases from the site, and it illustrates an extreme, progressive state of caries and the absence of dental hygiene. Dental Anthropology 2006;19(3):79-82.

were present among the Yajuz people. The present study presents one of the progressive cases of acute periapical abscesses and periodontal disease. This analysis also extracted the demographic variables of age and sex based on morphology of the cranium and development of the teeth. Dealing with the case from a forensic perspective, the study elucidates the probable cause of death.

\section{MATERIALS AND METHODS}

The study deals with the remains of one individual represented by a cranium that is dated to the Byzantine period, ca. 5th-8th century AD (Khalil, 1998, 2001). This cranium was visually assessed for the presence of periapical abscesses, caries, dental wear, and periodontal disease. The sex was estimated after Ascádi and Nemeskéri (1970), aging after Ubelaker (1989), wear according to Smith (1984), and abscesses and caries after Buikstra and Ubelaker (1994).

\section{RESULTS AND DISCUSSSION}

The supraorbital margins are very sharp with only minor prominence of Glabella, indicating that the specimen was female. The third right upper molar is not in complete occlusion; it is below the level of the adjacent right second molar. This situation suggests an age of about 21 years (Ubelaker, 1989).

The maxilla retained five teeth, namely the right canine, right first premolar, right second molar, right third molar, and left first premolar. The other teeth were lost before death (premortem) or around death (perimortem).

*Correspondence to: Abdulla Al-Shorman, Department of Anthropology, Faculty of Archaeology and Anthropology, Yarmouk University, Irbid-Jordan

E-mail: alshorman@yu.edu.jo 


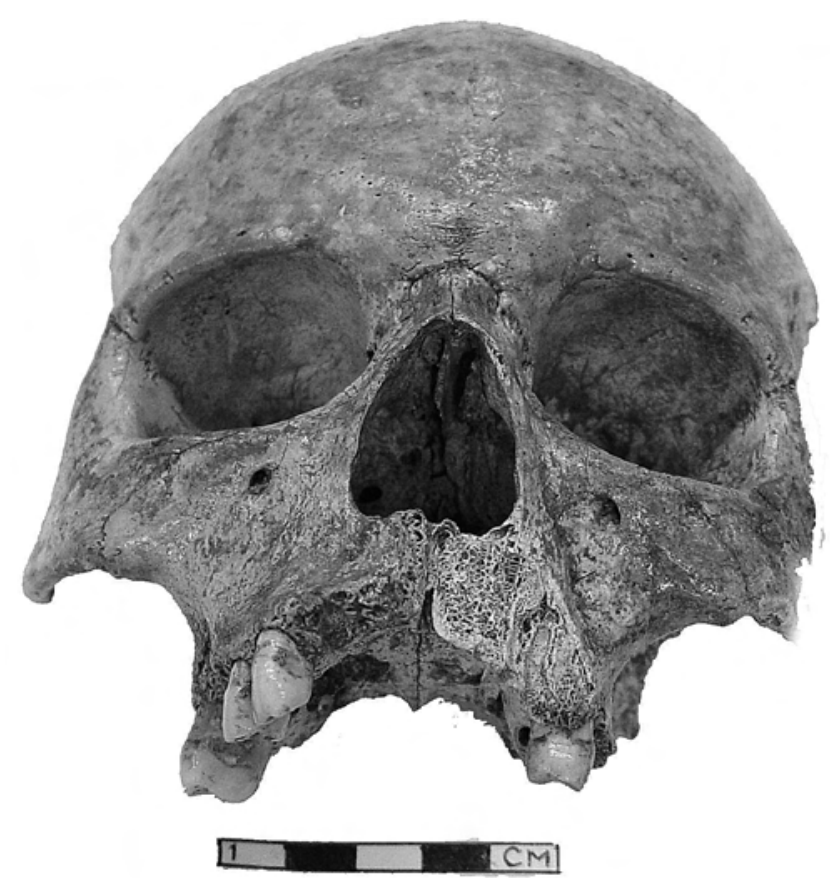

Fig. 1. An anterior view of the cranium. Photographed by Y. Al-Zou'bi.

The teeth that are present in occlusion exhibit minor dental wear, suggesting that the woman had a less abrasive diet and/or the teeth did not have enough time to be abraded because she died at a young age. The second right molar possesses two large caries, one on the mesial and the other on the distal cervical
TABLE 1. Maxillary tooth inventory

\begin{tabular}{lll}
\hline Tooth type & Side & \multicolumn{1}{c}{ Occlusion } \\
\hline First incisor & Right & Premortem loss \\
Second incisor* & Right & Perimortem loss \\
Canine & Right & Complete occlusion \\
First premolar & Right & Complete occlusion \\
Second premolar* & Right & Perimortem loss \\
First molar* & Right & Perimortem loss \\
Second molar & Right & In full occlusion \\
Third molar & Right & Below full occlusion \\
First incisor & Left & Postmortem loss \\
Second incisor & Left & Postmortem loss \\
Canine & Left & Postmortem loss \\
First premolar & Left & Postmortem loss \\
Second premolar & Left & In full occlusion \\
First molar & Left & Premortem loss \\
Second molar* & Left & Perimortem loss \\
Third molar* & Left & Perimortem loss \\
\hline
\end{tabular}

*Tooth exhibits a periapical abscess.

margin of the crown. The left second premolar also has a moderate lingual surface caries. Periodontal disease is prominent along the tooth arcade, with significant horizontal alveolar bone loss.

Five teeth exhibit periapical abscesses in advanced stages (Table 1). The most noticeable and advanced

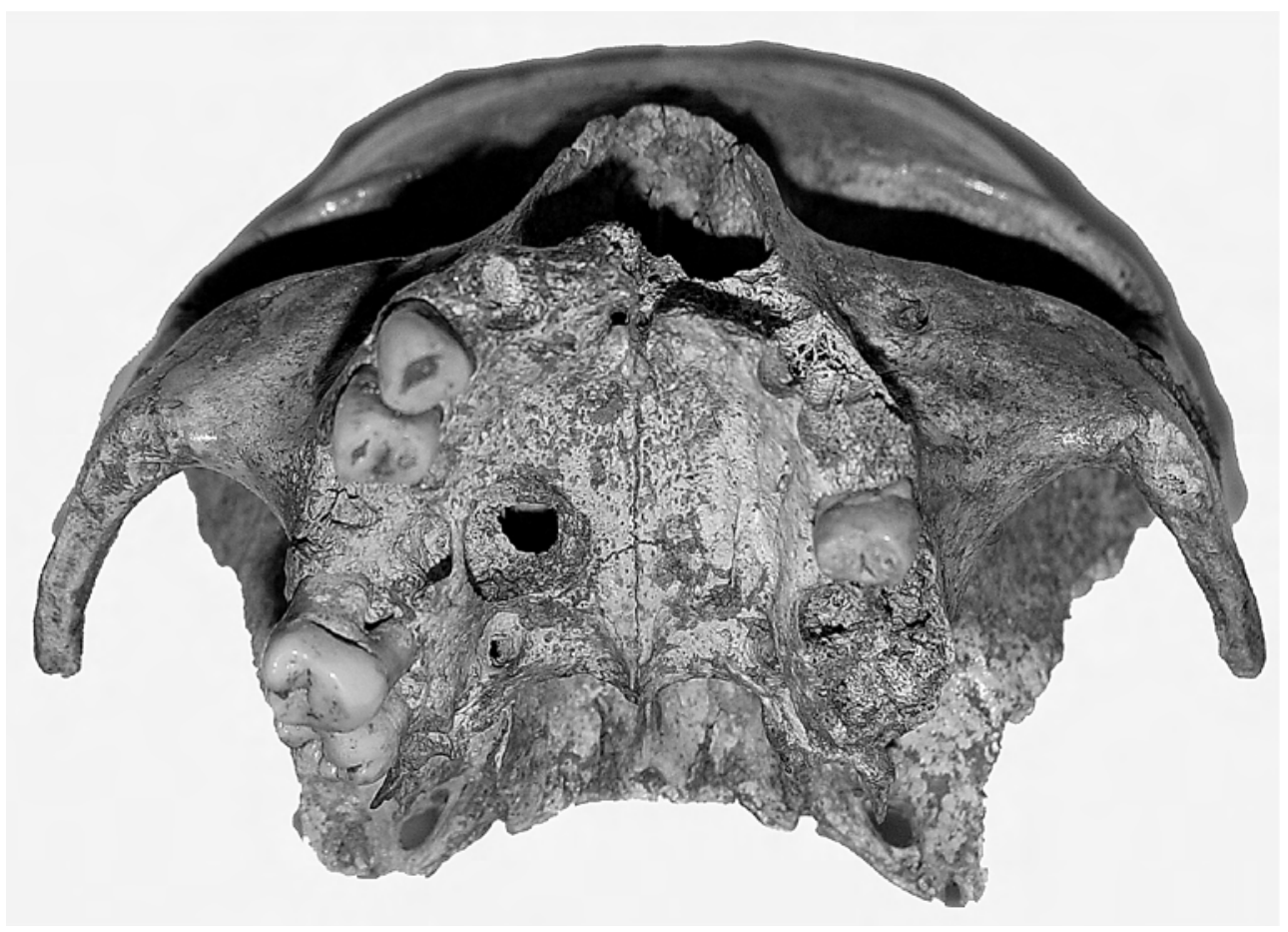

Fig. 2. Inferior view of the cranium showing the abscesses, dental caries and dental wear. Photographed by Y. Al-Zou'bi. 


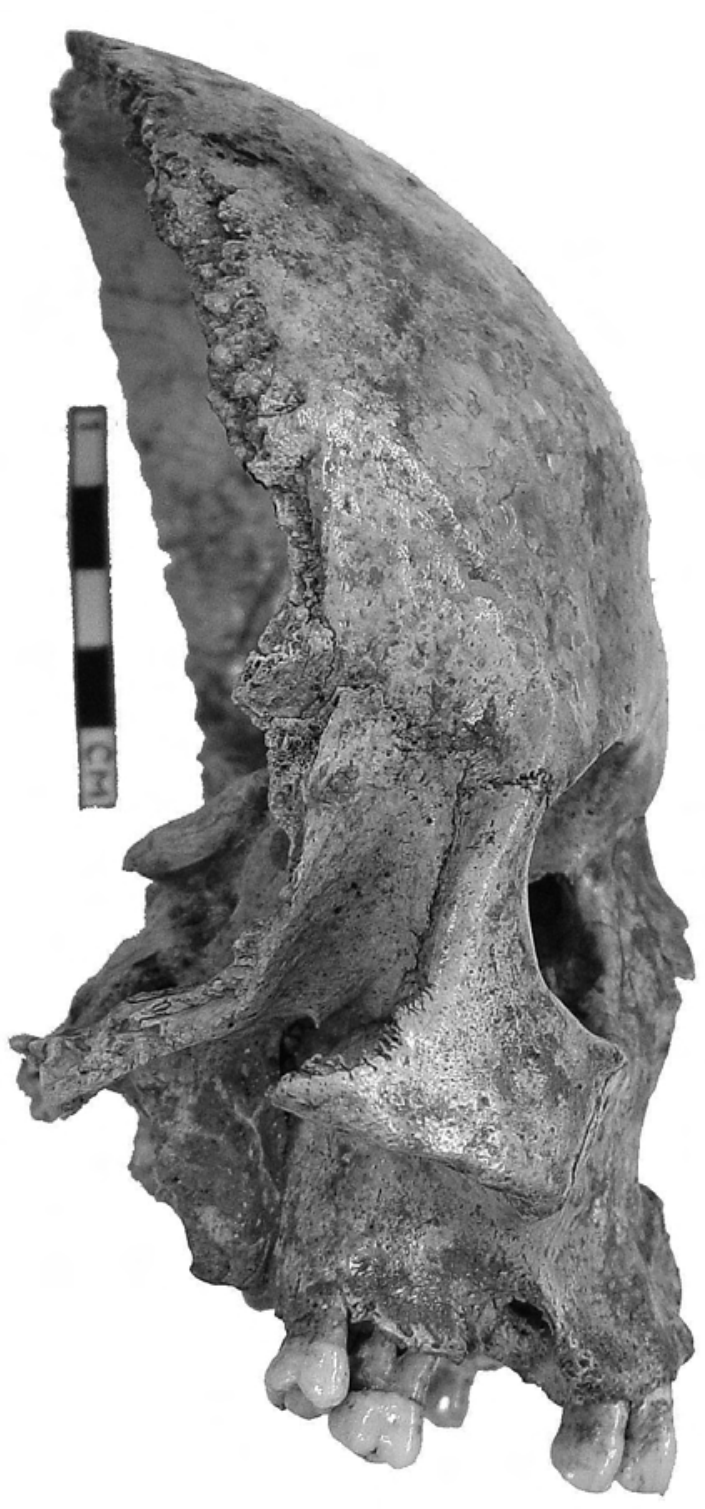

Fig. 3. Right lateral view showing bone destruction due to periodontal disease. Also note the buccal alveolar perforation and the lacrimal bone destruction. Photographed by Y. Al-Zou'bi.

one is the right first molar; perforations are present on the buccal and lingual sides of the alveolus. The pus accumulation was so destructive that the surrounding alveolar bone was resorbed for $8 \mathrm{~mm}$ above the buccal alveolar line. This resorption also exposed two-thirds of the adjacent second molar root. The amount of pus accumulation was certainly substantial: where it first formed a cyst in the palatine bone and then perforated the hard and soft palates, the fistula is about $3 \mathrm{~mm}$ in diameter. The pus seems to have accumulated in the nasal cavity; it is conceivable that the accumulated pus was running out of the individual's nose and mouth before death. The pus had also resorbed the nasal wall of the right maxillary sinus and the medial wall of the right orbit (the lacrimal bone). Edges of the perforation of the lacrimal bone are smooth and almost oval in shape.

The presumed large amount of pus in the nasal cavity and the maxillary sinuses might have been absorbed by the epithelial tissues lining them. The pus probably infiltrated the blood stream causing septicemia. Since the person died during the active stage of the disease, septicemia is the probable cause of her death. The progress of the disease was from the root of the first molar to the palatine bone, followed by the nasal cavity, and then involvement of the maxillary sinus. Finally, the orbit was involved, all of which took a considerable amount of time, probably weeks. This extensive invasion stresses the woman's physiological ability to tolerate and cope with the disease, especially in the absence of medical intervention.

\section{CONCLUSION}

The multiple dental pathologies in this case involve a clear-cut situation of poor dental hygiene in the presence of a rich carbohydrate diet. Comparable multiple pathologies were common among the people of Khirbit Yajuz, especially among skeletal remains of the low social classes. Our case is from the Yajuz people; the woman belonged to a low social class and probably died of septicemia at around 21 years of age.

\section{LITERATURE CITED}

Ascádi G, Nemeskéri J. 1970. History of human life span and mortality. Budapest: Akadémiai Kaidó.

Alexandersen V. 1967. The pathology of jaws and temporomandibular joints. In: Brothwell D, Sandison A, editors. Diseases in antiquity. Springfield: Charles C Thomas, p 551-595.

Al-Shorman A. 2003. A Byzantine tomb from Khirbit Yajuz, Jordan. J Paleopathology 15:177-185.

Al-Shorman A, Khalil L. 2006. The evidence of weaving at Khirbit Yajuz in Jordan using dental microwear. Int J Dental Anthropol 8:1-9.

Buikstra J, Ubelaker D. 1994. Standards for data collection from human skeletal remains. Arkansas Archaeological Survey Research Series. Fayetteville: Arkansas Archaeological Survey Research Series.

Hillson S. 1996. Dental anthropology. Cambridge: Cambridge University Press.

Khalil L. 1998. University of Jordan's excavations at Khirbit Yajuz. Annual of the Department of Antiquities Jordan 42:457-472.

Khalil L. 2001. Glass vessels from and miniature jugs from Khirbit Yajuz cemetery, Jordan. Levant 33:127138.

Powell M. 1985. The analysis of dental wear and caries for dietary reconstruction. In: Gilbert R Jr, Mielke J, editors. The analysis of prehistoric diets. Orlando: Academic Press, p 307-383.

Scott GR, Turner CG II. 1988. Dental anthropology. Ann 
Rev Anthropol 17:99-126.

Smith B. 1984. Patterns of molar wear in huntergatherers and agriculturalists. Am J Phys Anthropol 63:39-56.

Smith P, Horowitz L, Dujovny L. 1992. The human remains from area $\mathrm{H}$. In: de Groot A, Ariel D, editors. Excavations at the city of David 1978-1985. Vol. III. Stratigraphical, environmental, and other reports. QEDEM Monographs of the Institute of Archaeology, 33. Jerusalem, Israel: The Institute of Archaeology, The Hebrew University of Jerusalem.
Ubelaker J. 1989. Human skeletal remains, 2nd ed. Washington, DC: Taraxacum Press.

Williams K, El-Najjar M, Rose J, Al-Koufahi H, King M, Al-Awad F. 2004. Skeletal biology. In: Rose J, Burke $\mathrm{D}$, editors. A late Byzantine site in North Jordan. Irbid, Jordan: Yarmouk University Press, p 146-180. 